\title{
The Struggle against the Pandemics Requires a Systemic Approach
}

\author{
Oleg N. Yanitsky, Ph.D.,* \\ Professor, Chief Researcher, Federal Center of Theoretical and Applied Sociology of the Russian Academy of \\ Sciences. Address: Krzhizhanovskogo Str., 24/35, bld. 5, 117218, Moscow, Russia. \\ *Corresponding Author: Oleg N. Yanitsky, Ph.D., Professor, Chief Researcher, Federal Center of \\ Theoretical and Applied Sociology of the Russian Academy of Sciences. Address: Krzhizhanovskogo Str., \\ 24/35, bld. 5, 117218, Moscow, Russia.
}

\begin{abstract}
The article presents the first attempt to analyze the scientific, social and political roots of the current pandemics and its numerous consequences. I consider the pandemics attack as a systemic, allembracing and all penetrating critical situation (hereafter the CS) to which humanity has no adequate antidote. This CS is deeply rooted in the nature of domination of business-power tandem burdened with the new opportunities offered by the Fourth industrial revolution (hereafter the STR-4). The main features of the current global state of affairs are as follows. First, the scientists and scholars have been totally unprepared to such total and all-embracing attacks from the side of the viruses which are the part of our natural environment. Second, therefore the politics of struggle with the pandemics has a 'post factum' character i.e., as $U$. Beck defined it, we are still living in a society of the after-effects. Third, such politics and mode of scientific thinking is deeply rooted in the political and scientific tradition of humanity which can be labelled as a reactive one which in turn can be labelled as a reactive one. Four, the global stakeholders are first of interested in the dynamics of the global market and not in the laws and dynamics of natural processes. I call such shift as an economic technocracy. Five, the global stakeholders have still ignored the fact that our planet is a living organism which has its limited carrying capacity. Six, it follows that any partial and post factum offensive measures against the pandemics are inefficient since they lead towards the unrestored (irreplaceable) economic, social and natural losses. Seven, actually our planet is a complex sociobiotechnical organism (hereafter the global SBT system) with still unknown twists, bifurcations and feedbacks.
\end{abstract}

Keywords: critical situation, dynamics, globalization, pandemics, stakeholders, ecological, systemic and interdisciplinary approaches, the global SBT-system, the STR-4

\section{The STATE OF MATTERS}

Let me briefly to count what the struggle with current pandemics clearly showed to the social and natural sciences.

(1) Our global community including the scientists and scholars has been totally unprepared to such total and all-embracing attacks from the side of the viruses which are the part of our natural environment. It means that our understanding of its nature has been one-sided;

(2) The current pandemics and its after-effects are subjected to common laws of global development. Any global or local processes have nonlinear and probable character accompanied with unintended turns, twists and bifurcations.

(3) It means that the politics of struggle with the pandemics has a 'post factum' character i.e., as U. Beck defined it (Beck, 1999), we are still living in a society of the after-effects, and our struggle with the pandemics has the same character.

(4) Such politics and mode of scientific thinking is deeply rooted in the political and scientific tradition of humanity which can be labelled as a reactive one. From ancient times until now we keep to this mode of thinking and doing. Since a main ruler of our activity is a global market we first of all keep to its twists and turns.

(5) It follows that the global stakeholders are first of all keep in mind the dynamics of the global market and not the laws and dynamics of natural processes. I call such shift as an economic technocracy which sees a man as the governor and the nature as an unlimited source of resources. 
(6) In turn it means that the further the more our scientific model (picture) of the globalization process is failed to keep pace with its development. One of the main causes of current critical situation is an unknown to us the regularities of the emergence and development of the pandemics (Kravchenko, 2020).

(6) The global stakeholders have still ignored the fact that our planet is a living organism which has its limited carrying capacity. These actors forget the basic laws of ecological approach constructed by the US biologist B. Commoner (Commoner, 1971). They are as follows: all interconnected with the all, all is going somewhere, and nothing is given for gratis. It is they the main principles of both ecological and systemic analysis.

(7) It follows that any partial and post factum offensive measures are inefficient since they lead towards the unrestored (irreplaceable) economic, social and natural losses.

(8) We will be able to withstand to any critical situation if our scientific concepts will adequately resemble a structure and function of our planet and its cosmic space.

(9) It means that our planet is a complex sociobiotechnical organism (hereafter the global SBT system) with still unknown twists, bifurcations and feedbacks (Yanitsky, 2016).

(10) If the global SBT system is a complex and mobile organism we should practice a systemic and interdisciplinary approach developed in a space and time. The catastrophes of Exxon Valdes tanker, the accident at the Mexican Bay and recent accident in the Norilsk city in Russia are confirmed the necessity of such approaches.

(12) The above approach means that the global prognostics came to the forefront and took place on the global agendas. The current pandemics could be conquered by joint efforts of global scientific and policy-making community only.

(13) It means that an institute of science has to be the independent social and political force and not the servant of global economic and political stakeholders. This transformation is very important because thesestakeholders and their mass-media have become a main instrument of a shaping mass consciousness (Arsenalt and Castells, 2008) while the scientific knowledge is often used as kind of confirmation of already made decisions.

(14) It signifies that our urgent aim is to construct a joint scientific-economic-political and environmental task force. Such international teams have to develop some common principles of global collaboration for future forecasting, forecasting and developmental planning. The survival of separated groups or communities is a deadlock.

(15) The ultimate goal and basic principle of such collaboration and simultaneously the imperative of decision-making and developmental planning are our common future.

\section{Some Methodological ANd TheORETICAL CONSIDERATIONS}

(1) Under recent conditions of total interdependence of any (micro, middle and macro) structuralfunctional elements of our word they should be considered as the parts of a global ecosystem. From my viewpoint, the systemic and ecological approaches are the two sides of the same coin, and it's hard to define which of them is more theoretically applicable;

(2) The recent society is not only the global SBT-system but at the same time it is a part of cosmic system. Their structure, functions and dynamics are still under investigation. It signifies that our global complexity is not only the SBT-system but cosmic one which regularities are still uncertain to us, the sociologists.

(3) Nevertheless, if we rely upon the astronomic researches which stated that the solar energy emissions have happened usually every 20-25 years while the economic crises have happened every 10-12 years, we may to state that our planet and cosmic spare are living in a certain oscillation regime. It's important to mention that all living organisms are living in the same oscillation regime.

(4) Then, the principle of asymmetry should be introduced in a global scientific theory and practice. The further the more any social activity has asymmetrical character. To launch any action including those that has aggressive character is usually much easier than to complete such invasion.

(5) The principle of unequal response. This principle is a result of accumulation of negative social energy. An unmotivated individual social aggression (violence, repressions, vandalism, etc.) may 
generate massive negative reactions (protests, rallies, destructive activity) that we see now in the US, the EU and in some other parts of the world.

(6) After then, as any environment is a living organism, it should be considered as a complex social actor. And its response to any interference in its structure and functioning has asymmetrical character as well.

(7) Then, all kinds of environment have usually a hybrid character. Some of its structures are more or less inert to any interference from outside while the others are very sensitive to such invasion. It's one more reason to see the agent-environment interactions as asymmetrical ones.

(8) Afterwards, there is a great difference between the crises and critical situations. The crises (usually economic or political) usually have spatially and temporally-fixed character. The critical situations have quite different features. Firstly, they are, as a rule, have all-embracing and allpenetrating character. That is are the global phenomena. Secondly, they are the results of one-sided development. I consider the current pandemics as an outcome of imbalance between the science and economic development, between the permanent development of nuclear weapons and a lack of the interest to the biological arms, etc.

(9) Today, when all interconnected with all the usual political oppositions such as war or peace, here and there, close and distant are effaced. A micro and macro elements (structures, functions) are equally significant in the life of the global human community. I mean the 'power of the weakness' phenomenon.

(10) The current pandemics clearly showed that it should be investigated by the eco-systemic approach when all types of ecosystems (natural, social, technical) are tightly interconnected with each other.

(11) The politics of the struggle against the pandemics has been carried out by the administrative methods (bans, restriction, isolation and self-isolation) and not based on a complex and systemic approaches. It follows that this global epidemic has been perceived and mitigated as a national threat which has to be mitigated by two means. The former is the abovementioned restriction methods while the latter is total mobilization of national medical forces.

(12) As it has been already mentioned, a multisided, nonlinear and uncertain dynamics of the global SBT-system requires the systemic and interdisciplinary studies and a new research apparatus (approaches, methods, new relationships between theory and practice, etc. as well as between them and their environment).

(13) In turn, it means the rejection of the researchers from the partial, i.e. branch or departmental and mainly technological approaches to national and international development such as an 'optimization', digitalization, national projects, particular instructions, etc., and a decisive turn toward a systemic prognostic and to the compiling of interdisciplinary global-local projects.

(14) The last but not least, and is very important. Any global systemic or ecological analysis is relied upon the concept of metabolic processes, be it between natural processes or beings or between them and social and geopolitical processes of micro, middle and macro scale. The theoretical foundation of global metabolism has been developed by the Vienna school of interdisciplinary studies (FisherKowalski, 1997; Fisher-Kowalski and Haberl, 2007; Fisher-Kowalski and Erb, 2016; FisherKowalski, Krausmann and Winiwater, eds. 2016). But a direct metabolism of a solar energy into a food and other products for man named by the well-known Russian scientist Vl. Vernadsky as the autotrophic of humanityhas yet not been reached (Vernadsky, 1980). Anyhow, the world is now entering into a new 'transition period' (Yanitsky, 2019). It will be the transition not within already existed capitalist system, but the transition into new unknown period of human evolution burdened by well-known and unknown conflicts and wars under conditions ofa resource deficit and a continued growth of world population.

\section{A Man Under the All-Penetrating Pandemics}

A cocoon of the basic trust (A. Giddens) or the privacy or in my own interpretation the primary ecostructure (Yanitsky, 2012) has always been a basic element of social structure of a capitalist society. Nevertheless, within this society there are many other basic elements of this society such as the smack groups, communes, casts, ethnic and religious groups and societies. 
A global information-communication network created in the run of the Fourth scientific and technological revolution began to destroy these evolutionary-shaped basic units of human life replacing them by various kinds of the virtual units and networks. Nevertheless, a threat of hacker's attacks against such units has remained. But this threat to human privacy and how to cope with it is more or less understandable to the majority of population.

A threat of the pandemics is a quite another story. This threat is actually all-embracing and allpenetrating. And except a total self-isolation of every individual and a partial isolation of him from a habitual way of social life the carriers of this infection may be any element of his/her habitual living environment (people, things, goods, domestic animals, etc.).

The viruses are the unseen and unpredictable deadly danger, and this socio-psychological fact has exerted the negative influence on human consciousness and behavior.

All said above means that not only the scientists and scholars but the humanity at large are needed in a new, global concept of a social ecology because already existed developments being very interesting as such are not fit to the new state of matters (see, for example, Stokols, 2018).

In any case a man is a public being. And the attempts to transform him in an adjustment of the smart machines, masses of jobless or in the wasted people, i.e. in the pariah of the society will inevitably lead to protest movements and social resistance.

\section{CONCLuSion}

The systemic approach and the ecological ones are the two sides of the same coin because they are both are based on the all-embracing and all-interdependence principles.

Not only the sociology but the scientific community as a whole is still ill-prepared to the modern wars. It has happened because the sociology isn't a systemic discipline. As the pandemics clearly showed, the gap between a systemic character of the past and current warship events hasn't been resembled in the sociological investigations. The modern sociology has still ignored the well-known fact that the war is still one of the forms of humanity existence.

It's rather indicative that the sociologists and naturalists have interpreted the Fourth Scientific and Technological Revolution one-sidedly making accent on the opportunities offered by the Technological Revolution i.e. on new technologies of the information and communication systems. The administrative measures of the struggle against the pandemics are a direct result of this technocracy approach.

In order to cope with such phenomenon as the pandemics we should to develop the system approach to global studies and the systemic drivers of humanity development and not the oases of the start-ups and other forms of so-called 'outstripping development' only.

We, the sociologists and other humanitarians, have to comprehend the cumulative negative results of the pandemics. The matter isn't only in the forceful self-isolation of population as an administrative measure of a defense from the pandemic's attack. The matter is in the massive economic and social losses as unemployment, a massive outflow of well-educated young specialists to the West, etc.

Besides, it's already clear that the pandemics have provoked a rapid replacement of workers by the various forms of the smart technological devices. This trend is especially dangerous because the people are losing their moral and cultural reference-points. The overall population began to realize that the safety is becoming such reference-point.

The other important reference-point is a speed of a coming of certain global disaster. The current pandemics clearly showed that an acceleration of the speed of human communications across the world generated by the information revolution has its dark side, namely a very quick spreading of unknown infections and other treats to human health and well-being.

Thus, humanity has entered into the process on uninterrupted qualitative transformations. It means that the research instruments will be in process of permanent transformations, and therefore a state of a 'marginality' i.e. permanent transformations will be one of the main features of such changes. In turn, the concept of the 'scientific revolutions' (T. Khun) should be reconsidered.

The current pandemics and its outcomes have made obvious a systemic character of modern world. And the various metabolic processes are the keys for the understanding and sociological interpretation 
of ongoing systemic transformations. It follows that the cycle of the science-practice development, that is the 'science - teaching - civil activism' triad and vice versa is absolutely important.

A total digitalization, the dream of the technocrats may cause to humanity not less threat than the pandemics. To my mind, the techno-science and its devices are able to make some working and other processes easier and shorter but it has its own limits. A man is a public being. And the attempts to convert him in an adjustment of the smart machines, masses of jobless or in the wasted people, i.e. in the pariah of the society will inevitably lead to protest movements and social resistance.

In sum, the functioning of the above triad has to outstrip the evolution of global SBT-system.

The tandem of modern sciences and technologies has made our world more vulnerable. Therefore, a new concept of sociobiotechnological dynamics of the global SBT-systemas well as of its feedbacks with humanity is needed.

\section{REFERENCES}

[1] ArsenaultA. and Castells M. 2008. Switching Power: Rupert Murdoch and the Global Business of Media Politics. International Sociology 23(4): 488-513.

[2] Beck U. 1999.World Risk Society. Malden, MA: Polity Press. 184 pp.

[3] Commoner B. 1971.The Closing Circle. New York: Knopf.

[4] Fisher-Kowalski M. 1997. Society's Metabolism: On the Childhood and Adolescence of a Rising Conceptual Star, in Redklift M. and G. Woodgate, eds. The International Handbook of Environmental Sociology. Northampton, MA: Edward Elgar. Pp.119-137.

[5] Fisher-Kowalski M. and Haberl H. 2007.SocioecologicalTransitions and Global Change.Trajectories of Social Metabolism and Land Use. Vienna: Klagenfurt University.

[6] Fisher-Kowalski M. and Erb K.-H. 2016. Core Concepts an Heuristics, pp. 29-60, in: Haberl H., FisherKowalski M., Krausmann F. and Winiwater V., eds. 2016. Society-Nature Relations across Time and Space. ISBN (on-line): 978-3-319-33326-7.

[7] Available at: http://link.springer.com/book/10.1007\%2F978-3-319-33326-7

[8] Kravchenko S. 2020. Being Cosmopolitan and Anti-Cosmopolitan-The Complex Risks of the Covid-19: The Demand to Move from the Society of Normalization to 'Global Medical Surveillance.' European Sociologist, Issue 45 Vol. 1. URL: https://www.europeansociologist.org/issue-45-pandemicimpossibilities-vol-1/theorising-being-cosmopolitan-and-anti-cosmopolitan-complex-risks(last access: 11 June, 2020).

[9] Stokols D. 2018.Social Ecology in the Digital Age.Solving Complex Problems in a Globalized World. Univ. of California: Academic Press. 399 pp.

[10] Vernadsky V. 1980.Some Words on the Biosphere, pp. 228-245, in: Vernadsky V. Problems of a Geochemistry.Works of Biogeochemical Laboratory. Moscow: Nauka. 320 pp. (in Russ.)

[11] Yanitsky O. 2012. A Primary Eco-Structure: The Concept and its Testing. Social Analysis, Vo.2, No 2, pp. 7-24.

[12] Yanitsky O. 2016. Sociobiotechnical systems: a New Approach to Man-Nature Interactions, in: Yanitsky O. On Globalization and its Environmental Consequences. Moscow: IS RAS' pp. 123-135. Available at: http://www.isras.ru/index.php?_id1198\&id=4603

[13] Yanitsky O. 2019. A Transition Period: The Aims of the Study, Theory and Practice. Moscow: Russian Political Encyclopedia. 287 pp. (In Russ.)

Citation: Oleg N. Yanitsky, Ph.D. "The Struggle against the Pandemics Requires a Systemic Approach" International Journal of Humanities Social Sciences and Education (IJHSSE), vol 7, no.76, 2020, pp. 67-71. doi: http://dx.doi.org/10.20431/2349-0381.0707007.

Copyright: (1) 2020 Authors. This is an open-access article distributed under the terms of the Creative Commons Attribution License, which permits unrestricted use, distribution, and reproduction in any medium, provided the original author and source are credited. 